\title{
MACRO CREDIT SCORING COMO PROPUESTA PARA CUANTIFICAR EL RIESGO DE CRÉDITO
}

\section{Sergio Edwin Torrico Salamanca}

\section{RESUMEN}

El Credit Scoring es una metodología utilizada en finanzas, para cuantificar el riesgo de crédito de individuos/empresas, este artículo propone la aplicación de esta técnica como una herramienta para medir el riesgo de crédito agregado de los bancos, y del sistema bancario. Se presenta una aplicación en el sistema bancario comercial boliviano, con el objetivo de exponer la metodología propuesta, denominada Macro Credit Scoring. Mediante la aplicación de la metodología, se identifica que la medida de riesgo aplicada es superior a la necesaria en el sistema bancario comercial boliviano en la coyuntura actual. Finalmente se presenta evidencia empírica de la relación entre el riesgo de crédito y las variables económicas (macro/micro)

Palabras clave: Credit Scoring, Administración de Riesgos, Riesgo de Crédito, Banca. 